\title{
Downscaling climate change scenarios for apple pest and disease modeling in Switzerland
}

\author{
M. Hirschi ${ }^{1}$, S. Stoeckli ${ }^{2}$, M. Dubrovsky ${ }^{3}$, C. Spirig ${ }^{1}$, P. Calanca ${ }^{4}$, M. W. Rotach ${ }^{1, *}$, A. M. Fischer ${ }^{1}$, B. Duffy ${ }^{2}$, and \\ J. Samietz ${ }^{2}$ \\ ${ }^{1}$ Federal Office for Meteorology and Climatology MeteoSwiss, Krähbühlstrasse 58, 8044 Zürich, Switzerland \\ ${ }^{2}$ Agroscope Changins-Wädenswil Research Station ACW, Schloss, P.O. Box 185, 8820 Wädenswil, Switzerland \\ ${ }^{3}$ Institute of Atmospheric Physics ASCR, Boční II 1401, 14131 Prague 4, Czech Republic \\ ${ }^{4}$ Agroscope Reckenholz-Tänikon Research Station ART, Reckenholzstrasse 191, 8046 Zürich, Switzerland \\ * present address: University of Innsbruck, Institute for Meteorology and Geophysics, Innrain 52, 6020 Innsbruck, Austria
}

Correspondence to: M. Hirschi (martin.hirschi@meteoswiss.ch)

Received: 18 August 2011 - Published in Earth Syst. Dynam. Discuss.: 25 August 2011

Revised: 16 January 2012 - Accepted: 26 January 2012 - Published: 27 February 2012

\begin{abstract}
As a consequence of current and projected climate change in temperate regions of Europe, agricultural pests and diseases are expected to occur more frequently and possibly to extend to previously non-affected regions. Given their economic and ecological relevance, detailed forecasting tools for various pests and diseases have been developed, which model their phenology, depending on actual weather conditions, and suggest management decisions on that basis. Assessing the future risk of pest-related damages requires future weather data at high temporal and spatial resolution. Here, we use a combined stochastic weather generator and re-sampling procedure for producing site-specific hourly weather series representing present and future (1980-2009 and 2045-2074 time periods) climate conditions in Switzerland. The climate change scenarios originate from the ENSEMBLES multi-model projections and provide probabilistic information on future regional changes in temperature and precipitation. Hourly weather series are produced by first generating daily weather data for these climate scenarios and then using a nearest neighbor re-sampling approach for creating realistic diurnal cycles. These hourly weather series are then used for modeling the impact of climate change on important life phases of the codling moth and on the number of predicted infection days of fire blight. Codling moth (Cydia pomonella) and fire blight (Erwinia amylovora) are two major pest and disease threats to apple, one of the most important commercial and rural crops across Europe. Results for the codling moth indicate a shift in the occurrence and duration of life phases relevant for pest control. In southern Switzerland, a 3rd generation per season occurs only very
\end{abstract}

rarely under today's climate conditions but is projected to become normal in the 2045-2074 time period. While the potential risk for a 3 rd generation is also significantly increasing in northern Switzerland (for most stations from roughly $1 \%$ on average today to over $60 \%$ in the future for the median climate change signal of the multi-model projections), the actual risk will critically depend on the pace of the adaptation of the codling moth with respect to the critical photoperiod. To control this additional generation, an intensification and prolongation of control measures (e.g. insecticides) will be required, implying an increasing risk of pesticide resistances. For fire blight, the projected changes in infection days are less certain due to uncertainties in the leaf wetness approximation and the simulation of the blooming period. Two compensating effects are projected, warmer temperatures favoring infections are balanced by a temperature-induced advancement of the blooming period, leading to no significant change in the number of infection days under future climate conditions for most stations.

\section{Introduction}

Projected climate change is expected to lead to higher temperatures and less stable precipitation regimes in temperate regions of Europe, impacting the agricultural sector by increased risk of drought and heat waves (e.g. Meehl and Tebaldi, 2004; Schär et al., 2004; Hlavinka et al., 2009) or flooding (e.g. Christensen and Christensen, 2003; Frei et al., 2006), respectively. Beside these direct impacts, agriculture 
is also largely affected by indirect effects of climate change, such as changes in pest and disease populations (e.g. Trnka et al., 2007). The development, reproduction and distribution of arthropods are strongly determined by temperature (ectothermy). Consequently, both an earlier beginning and prolongation of the season, as well as distribution shifts poleward and to higher elevations, have been observed for many insect pests (Parmesan et al., 1999; Altermatt, 2010) and plant diseases (Coakley et al., 1999; Eastburn et al., 2011) in parallel with recent warming. With the projected further temperature increase, agricultural pests and diseases are expected to occur more frequently and possibly to extend to previously non-affected regions.

Already today, apple orchards are constantly threatened by pests and diseases, and the production depends on effective pest and disease control measures. In order to avoid unnecessary treatments and with regard to sustainable plant protection strategies, accurate pest and disease forecasting tools have been developed to predict the infestation, depending on actual weather conditions. The development of pests and diseases is most successfully predicted if the microclimate of the immediate environment (habitat) of the causative organisms can be simulated (Samietz et al., 2007). Assessing the risk of pest-related damages as a consequence of climate change therefore requires information on future weather for the pest-relevant habitats and on the appropriate time scale (i.e. hourly temporal resolution). It is well known that the output of climate models is not suitable for direct application to impact studies. There are two major issues: low spatial (and temporal) resolution and the presence of significant biases. The latter problem also affects the sequence of weather events. Thus, a statistical or dynamical downscaling needs to be applied (e.g. Calanca et al., 2009). While a dynamical downscaling is demanding in terms of computational resources, a statistical downscaling can be achieved with relatively small resources and is thus more attractive and feasible from a climate projection end-user perspective.

Here we developed and applied an application-specific statistical downscaling procedure based on the combination of a stochastic weather generator (WG, to generate daily weather series) and a subsequent re-sampling (to obtain hourly weather series) to translate probabilistic climate model scenarios into suitable weather series for pest and disease modeling. Stochastic WGs have been successfully applied to downscale information from climate scenarios (e.g. Wilks, 2002; Calanca et al., 2009; Semenov et al., 2010). Unlike the simple delta change approach (i.e. the additive/multiplicative scaling of historic records with projected climate change signals; e.g. Hay et al., 2000), the use of a stochastic WG allows for the generation of multiple realizations of the present and future climate, allowing assessing the uncertainty in the application model due to natural climate variability. Two basic categories of stochastic WGs are in use today. They differ in the applied precipitation model to simulate the sequence of wet and dry spells, namely Markov-chain based (or "Richardson-type"; Richardson, 1981) and spell-length model types (e.g. "LARS-WG"; Racsko et al., 1991). WGs of both types mainly operate on a daily time scale. Hourly outputs are less common, but can be realized by applying a re-sampling approach subsequent to the generation of the daily time series (e.g. Mezghani and Hingray, 2009; Dubrovsky et al., 2011). In general, the downscaling procedure needs to be designed for the requirements of the particular application, and its performance must be specifically tested for assuring an appropriate representation of the driving weather characteristics.

As a case study, we examined the influence of climate change in Switzerland (i.e. at the location of ten meteorological stations) on the future threat of codling moth (Cydia pomonella) and of fire blight. The codling moth is the major insect pest in apple orchards worldwide (Dorn et al., 1999); damage is caused by the larvae, which burrow into the fruit to feed on the flesh. Depending on the climatic condition (and genetically determined phenology), the species can form up to five generations per year in the warmest apple growing regions or only one generation in the coolest production areas (Riedl, 1983; Janjua et al., 1958). Fire blight is the most serious current and long-term threat to commercial production of apple and pear in Switzerland and across Europe (Bonn and van der Zwet, 2000). It is caused by the invasive quarantine pathogen Erwinia amylovora, which was first introduced from North America into the UK and Northern Europe in the late 1950s, and has spread throughout Europe over the past three decades (Jock et al., 2002). While the development of the codling moth is primarily a function of temperature and solar radiation, fire blight disease is additionally highly dependent on leaf wetness (induced by dew or rain).

In the present study we exemplify how to close the gap between climate change scenarios and impact modeling of pests and diseases on an hourly time scale. It is carried out in the framework of a national initiative to disseminate updated climate change scenarios for Switzerland (see Fischer et al., 2011, and the official CH2011 report: http://www.meteoschweiz.admin.ch/web/en/climate/ climate_tomorrow/scenario_2011.html). First we introduce the climate change scenarios together with the downscaling procedure, the applied pest and disease models, and the validation procedure. Then the results of the validation, the derived climate change signals, and the scenarios for codling moth and fire blight are presented and discussed, followed by an overall summary and conclusion.

\section{Methods}

\subsection{Climate change scenarios}

The climate change information was taken from the regional climate simulations of the EU-FP6 project ENSEMBLES (van der Linden and Mitchell, 2009). This database includes 
21 regional climate models (RCMs) driven by eight global climate models (GCMs), all simulating the A1B SRES emission scenario (Nakicenovic et al., 2000) in a transient mode covering at least the 1950-2050 time period. Here, the periods 2045-2074 vs. 1980-2009 were considered for the analysis, based on the subset of simulations (14 RCM-GCM chains with six GCMs involved) which ran beyond 2050. Note that the RCM-GCM chain "HIRHAM (DMI)" driven by "BCM (NERSC)" was excluded due to a simulation error reported by DMI at the time of this analysis (Fischer et al., 2011).

Using a Bayesian multi-model combination algorithm (Buser et al., 2009), the simulations were processed and aggregated to obtain seasonal probabilistic climate change signals of changes in temperature and precipitation for three domains in Switzerland (see Fig. 1). The spatial extent of the domains was determined semi-empirically based on the spatial correlation structure of temperature and precipitation. Note that assumptions inherent in many climate projections are that the range of model uncertainty is fully sampled by the available model projections, and that systematic model biases do not change with time. These assumptions were also made here (for more details, see Fischer et al., 2011).

Despite large improvements in climate modeling during recent years, climate change projections are still associated with considerable uncertainties. By considering a multimodel ensemble based on structurally different models, some of this uncertainty can be taken into account (Tebaldi and Knutti, 2007). While the level of scientific understanding is reasonably high for temperature and precipitation, other climate variables or inter-annual variability (as compared to the climate mean) are less well simulated (e.g. due to limited process understanding). Thus, we confined ourselves to the inclusion of changes in the climate mean of temperature and precipitation (including the precipitation parameters intensity, frequency and dry-to-wet transition probability for the fire blight simulations, see below). In particular, we did not include simulated changes in relative humidity and solar radiation, as both still include considerable uncertainties (e.g. Wild, 2009; Sherwood et al., 2010).

From the probabilistic climate change signals, we considered three temperature and precipitation combinations for the investigation of climate change impacts on codling moth: the median signals of the multi-model projections for both mean temperature and precipitation, a combination of high temperature and low precipitation change, and a combination of low temperature and high precipitation change. These combinations cover the uncertainty range of the multi-model projections (as represented by the $95 \%$ confidence intervals of the posterior distributions, see Fischer et al., 2011) and are based on the assumption that changes in temperature and precipitation tend to be negatively correlated, at least during the summer season (e.g. Schär et al., 2004; Vidale et al., 2007). In addition, the full (and extended) range of the climate change signals was exploited using indicative temperature sums for

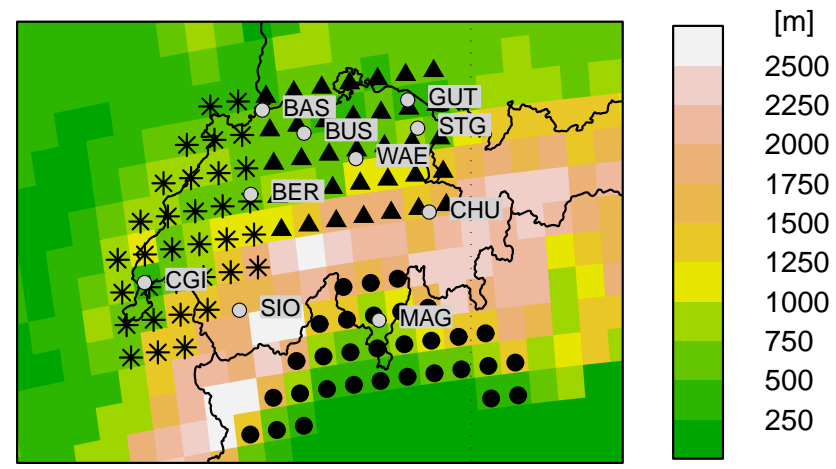

Fig. 1. Locations of the ten considered meteorological stations (gray dots, for the station names' abbreviations, see Table 2), as well as RCM grid points (black symbols) used to define the three domains for the aggregated climate change signals (see Sect. 2.1): northeastern $(\boldsymbol{\Lambda}, \mathrm{CHNE})$, western ( $*$ CHW) and southern $(\bullet, \mathrm{CHS})$ Switzerland. Both are mapped onto a topography at roughly the RCMs' spatial resolution. Note that CHNE combined with CHW is referred to as northern Switzerland in the text. Figure adapted from Fischer et al. (2011).

the occurrence of codling moth life phases instead of the full pest model (see Sect. 2.3.1).

In addition to mean temperature and precipitation, also changes in precipitation frequency and intensity, as well as changes in the transition probability from dry-to-wet days used in the Markov model of the stochastic weather generator (see Sect. 2.2), were included for the fire blight simulations, as infection with fire blight is triggered by humidity events (i.e. rain and leaf wetness, see Sect. 2.3.2). Only the median climate change signals were considered for the fire blight scenarios. The signals of the additional precipitation parameters were derived from the daily output of the ENSEMBLES RCMs. A wet-day threshold of $1 \mathrm{~mm} \mathrm{~d}^{-1}$ was applied to the raw precipitation model outputs to discriminate between wet and dry days (e.g. Frei et al., 2006). Precipitation intensity and frequency were then processed using the same Bayesian approach as in Fischer et al. (2011). For the parameter dry-to-wet transition probability, we solely computed the median change signal empirically using the raw model output of the ENSEMBLES RCMs and did not make use of the Bayesian algorithm. The reason for this approach lies in the difficulty to properly transform this parameter into a normally distributed variable given different model-chains, seasons, regions and time periods - an inherent assumption of the Bayesian algorithm (see Fischer et al., 2011). It would also heavily complicate the determination of the prior assumption. Note that the difference between the empirically derived median climate change signal and the one derived from the Bayesian algorithm is usually marginal as analyzed for the example of precipitation intensity, frequency, and its mean. This is because both approaches implicitly rely on the assumption of a constant model bias now and in a future climate (for more details we refer to Fischer et al., 2011). 
To ensure consistency between the median climate change signal in mean precipitation and the respective signals in precipitation intensity and frequency (changes in percent), the following approach was applied: as mean precipitation can be considered to be represented most reliably in the models among the three precipitation parameters, its median signal $\left(\Delta P_{\text {mean }}\right)$ from the climate models was kept unmodified. Then, based on the fact that the posterior uncertainty is generally smaller in the precipitation intensity signal $\left(\Delta P_{\text {int }}\right)$ than in the frequency signal $\left(\Delta P_{\text {freq }}\right)$, the median signal of the former was also not modified, but the signal of the latter was adjusted if required (i.e. treated as residual) in order to fulfill

$\Delta P_{\text {freq }}=\frac{1+\Delta P_{\text {mean }}}{1+\Delta P_{\text {int }}}-1$.

\subsection{Downscaling procedure}

To downscale the seasonal climate change information to the time scales relevant for the pest (i.e. hourly weather series at ten meteorological stations in Switzerland, see Fig. 1), a stochastic daily weather generator (WG) combined with a re-sampling approach was applied (HOWGH; Dubrovsky et al., 2011). The stations were selected based on the availability of long-term (i.e. covering the climate models' control period 1980-2009) hourly and daily meteorological observations for the calibration of the downscaling procedure, and of in situ pest observations for the validation (see Table 1 in the Supplement for an overview on the applied data sets). In a first step, synthetic daily weather series of precipitation, solar radiation and temperature (daily average and range) were produced using the parametric stochastic WG M\& Rfi (Dubrovsky et al., 2004), a Richardsontype WG (Richardson, 1981). It is based on a Markov chain to model precipitation occurrence, gamma distribution for the precipitation amount and an autoregressive model for non-precipitation variables (with conditioned statistics of the daily non-precipitation variables on occurrence or nonoccurrence of precipitation). The applied first-order Markov model is fully defined by the precipitation frequency and the transition probability from dry-to-wet days (see e.g. Wilks and Wilby, 1999). The stochastic WG was calibrated separately for each of the ten stations using the daily meteorological observations to obtain the parameter set for present climate (calibration period 1981-2009), which was subsequently adjusted with the climate change signals (see previous section). The parameters of the precipitation submodel were determined separately for the individual months of the year, and the means and standard deviations of the non-precipitation variables were defined for the individual days of the year, with annual cycles being smoothed by a robust locally-weighted regression (Solow, 1988). If changes in precipitation frequency were applied, the effect on the mean values of non-precipitation variables resulting from the difference between their conditioned wet-day and dryday means (e.g. increase in overall mean temperature with
Table 1. Median climate change signals (2045-2074 vs. 1980$2009)$ of mean temperature $\left(\Delta T_{\text {mean }}\right)$ and mean precipitation $\left(\Delta P_{\text {rmean }}\right)$ as presented in Fischer et al. (2011), as well as of precipitation intensity $\left(\Delta P_{\text {int }}\right)$, frequency $\left(\Delta P_{\text {freq }}\right)$, and dry-to-wet transition probability $(\triangle P 01)$ for the three Swiss domains (Fig. 1) and four seasons. Figures in bold denote significant signals with respect to the distribution of the multi-model climate change scenarios ( $5 \%$ significance level).

\begin{tabular}{|c|c|c|c|c|c|}
\hline & $\Delta T_{\text {mean }}{ }^{\circ} \mathrm{C}$ & $\Delta P_{\text {mean }}$ & $\begin{array}{r}\Delta P_{\text {int }} \\
\%\end{array}$ & $\Delta P_{\text {freq }}$ & $\begin{array}{r}\triangle P 01 \\
\%\end{array}$ \\
\hline \multicolumn{6}{|c|}{ Northeastern Switzerland (CHNE) } \\
\hline DJF & 2.3 & 0 & 3 & -2.9 & -2 \\
\hline MAM & 2 & 3.4 & 5.1 & -1.6 & -3 \\
\hline JJA & 2.6 & -10.4 & 2 & -12.2 & -17 \\
\hline SON & 2.2 & 0.9 & 7 & -5.7 & -3 \\
\hline \multicolumn{6}{|c|}{ Western Switzerland (CHW) } \\
\hline DJF & 2.3 & 1.4 & 4.9 & -3.3 & -2 \\
\hline MAM & 2 & -1.1 & 4 & -4.9 & -4 \\
\hline JJA & 2.7 & $-\mathbf{1 7 . 2}$ & -3 & -14.6 & -19 \\
\hline SON & 2.2 & -2.4 & 5 & -7 & -8 \\
\hline \multicolumn{6}{|c|}{ Southern Switzerland (CHS) } \\
\hline DJF & 2.4 & 9.7 & 5 & 4.5 & 5 \\
\hline MAM & 2.3 & -6.6 & -0.6 & -6 & -3 \\
\hline JJA & 2.9 & -13.2 & -2.5 & -11 & -13 \\
\hline SON & 2.3 & -3.8 & 2.4 & -6.1 & -5 \\
\hline
\end{tabular}

lower fraction of wet days) was offset when setting the mean change signals for these variables according to the model scenarios (Dubrovsky et al., 2000). Using the WG parameter sets for present and future climate conditions, $100 \mathrm{yr}$ of synthetic daily weather were generated in each case.

In a second step, a $k$-nearest neighbor re-sampling procedure was employed to disaggregate the daily weather series into hourly resolution. For each day of the synthetic weather produced by the daily WG, the ten most similar days (i.e. $k=10$ ) were selected from the hourly station observations within a \pm 10 -day time window around the corresponding day of year. The similarity was quantified by the Mahalanobis distance considering daily mean precipitation and temperature, daily temperature range, and solar radiation. From the selected ten daily cycles, one was randomly chosen. In a final step, a multiplicative (additive) fitting was applied to the hourly values of precipitation and solar radiation (temperature) to match the daily values generated by the WG. This fitting procedure is necessary as the daily averages of the selected daily cycles do not exactly fit the daily values used as predictors in the sampling procedure. In the case of temperature, also the midnight steps, which appear in the hourly series due to the fact that the daily cycles selected by the sampling procedure for neighboring days are 
not related, were reduced to obtain smooth transitions from day to day. As a part of the re-sampling procedure, relative humidity from the same chosen observation day was added to the hourly output. The resulting synthetic hourly weather series for present and future climate conditions ( $100 \mathrm{yr}$ of synthetic data in each case) were subsequently used to drive two pest and disease models at ten locations in Switzerland.

\subsection{Pest and disease modeling}

\subsubsection{Codling moth}

The development of the codling moth was simulated (1) as complete phenologies of all life stages and (2) with a simplified approach by using indicative temperature sums of key events in the life cycle. Thereby the forecasting and decision support system SOPRA (Samietz et al., 2007, 2008b) was used for detailed codling moth simulations. SOPRA is a modeling tool consisting of single species models, which include close approximations of the microclimatic condition as prerequisite for successfully modeling phenologies (Samietz et al., 2007). The system provides precise information about the presence of different life phases of insects depending on local climate and gives advice on the timing of corresponding management or monitoring activities. The development of the different life phases of codling moth was simulated in terms of relative phenologies (in percentage of the population), starting with the pupae of the hibernating generation $(100 \%)$. As the development of the codling moth is highly determined by temperature (see Sect. 1), the output of the codling moth model of SOPRA can be used to derive indicative temperature sums (i.e. the sum of hourly temperatures $>10^{\circ} \mathrm{C}$, which is the developmental zero of the codling moth post diapause development, see e.g. Howell and Neven, 2000) for different codling moth life phases. Using these indicative temperature sums, dates of occurrence (as day of year, DOY) can be derived for the various life phases and the development of the generations over the year can be modeled. Moreover, they enabled us to carry out sensitivity tests exploiting the full (and extended) uncertainty range of the probabilistic climate change signals (see Sect. 2.1). The temperature-sum thresholds for the different life phases were derived from SOPRA separately for each station.

The analyzed life phases included the flight start of the codling moth adults in spring after hibernation (first flight), eggs of the 1st generation, three phases for the hatching of the 1 st generation larvae (start, $20 \%$ and $45 \%$ of the population), the flight of the 1st generation (2nd flight), eggs of the 2nd generation, etc. Two temperatures were considered as basis for the calculation of the temperature sums describing codling moth life phases, stem $\left(T_{\text {stem }}\right)$ and air $\left(T_{\text {air }}\right)$ temperature. The former determines the flight start in spring, as the codling moth hibernates on the stem of the apple trees. It was modeled as a function of $T_{\text {air }}$ and solar radiation (SRAD), which is scaled to represent the effective solar radiation at the stem (see Samietz et al., 2008a):

$T_{\text {stem }}=T_{\text {air }}+$ const. $\cdot \operatorname{SRAD} \cdot\left(1-\frac{1}{1+e^{(4-(0.05 \cdot(\mathrm{DOY}-50)))}}\right)(2)$

with const. $=0.02279^{\circ} \mathrm{Cm}^{2} \mathrm{~W}^{-1}$. For the later life phases, $T_{\text {air }}$ is crucial for the development of the codling moth.

The additional benefit of SOPRA compared to the indicative temperature sums is the knowledge of the relative magnitude of the individual life phases (in \%), as well as the possibility to include a day-length signal, which determines the start of the hibernation (i.e. the diapause induction) and thus the absence of later life phases (see Sect. 3.3.1). The impact of climate change on the future threat of codling moth was assessed based on its influence on the pest phenology (shifts in occurrence of life phases, development of an additional 3 rd generation). In addition, the risk for the development of a 3rd generation was analyzed based on the probability of 3rd generation larvae starting to hatch.

\subsubsection{Fire blight}

Simulations of the bacterial disease fire blight are based on the forecasting model Maryblyt (Steiner, 1990; Steiner and Lightner, 1996; Duffy et al., 2008), which predicts infection days during the blossom period.

For an infection day indication, several conditions must be fulfilled:

- open blossoms (phenology)

- 110 cumulative degree-hours $(\mathrm{cDH})>18.3^{\circ} \mathrm{C}$ within the last 44.4 cumulative degree-days $(\mathrm{cDD})>4.4^{\circ} \mathrm{C}$

- daily mean temperature $>15.6^{\circ} \mathrm{C}$

- day with either dew/leaf wetness $(>2 h)$ or rain of $>0.25 \mathrm{~mm}$

- pathogen inoculum potential (assumed; BraunKiewnick et al., 2011).

When all these conditions are fulfilled, infection potential is indicated on the respective day. The impact of climate change on fire blight infections was assessed based on changes in the number of infection days per year, as well as on changes in the annual infection occurrence (i.e. occurrence and non-occurrence of infection in a particular year).

The blooming period was simulated with a temperaturesum model. Here we focus on the apple cultivar "Golden Delicious" as one of the main varieties globally. Using in situ observations of flowering dates of "Golden Delicious" in Switzerland from 1981-2010, the following temperaturesum model and thresholds for the beginning and the termination of the blooming period were derived (see also Stoeckli and Samietz, 2012): 
- temperature-sum model: sum of hourly temperatures $>0{ }^{\circ} \mathrm{C}$, starting day for summation $=$ DOY 45

- Beginning of bloom: $10590( \pm 1355) \mathrm{cDH}$

- Flowering termination: $15920( \pm 1425) \mathrm{cDH}$.

The occurrence of leaf wetness was simulated with an empirical relative humidity threshold. Such empirical approaches were shown to achieve almost as good results as mechanistic models once a canopy specific threshold could be defined (Wichink Kruit et al., 2008). It was applied on the hourly time scale, based on a threshold of $77 \%$ relative humidity above which leaf wetness occurs. This is an intermediate threshold based on the literature (e.g. Van Jaarsveld, 2004; Wichink Kruit et al., 2008).

\subsection{Validation of the downscaling procedure}

Validation of the downscaling procedure can be made in two ways, by a direct and an indirect validation. In the direct validation, climate and weather statistics of the synthetic hourly weather series for present climate conditions are compared to observed statistics to ensure consistency. This ensures that the basic weather statistics can be reproduced by the downscaling procedure.

However, the application might be more dependent on certain weather variables than on others. Thus, the downscaling procedure needs to be further validated to ensure that the modeling system as a whole successfully reproduces important characteristics of the particular application. In such an indirect validation, the application model (i.e. the pest or disease model) is driven with the synthetic weather series, and the output of the application model is then compared with in situ pest observations (if available), or with output from the application model driven with observed weather.

The indirect validation for the codling moth focused on the comparison of dates of occurrences of the flight start in spring. This life phase is particularly important as it determines (together with the onset of the hibernation in late summer) the length of the codling moth season. Moreover, the flight start depends on the stem temperature (see Sect. 2.3.1), which in turn is a function of air temperature and solar radiation. Thus, a successful representation of the flight start from the synthetic weather is a sound test for the downscaling procedure. The occurrence of later life phases was examined on the basis of their mean occurrences. For fire blight, the focus of the indirect validation was on the number of infection days per year. As infection risk is influenced both by temperature and leaf wetness (Sect. 2.3.2), the indirect validation for this application additionally provides a test on the performance of the downscaling procedure for simulating precipitation and humidity.

\section{Results and discussion}

\subsection{Validation}

Figure 2 shows the direct validation of the mean seasonal and daily cycles (in case of the latter for the application-relevant seasons and separately for dry and wet days) of temperature, precipitation and solar radiation at the station Wädenswil (WAE in Fig. 1). Compared are $29 \mathrm{yr}$ of in situ observations (1981-2009) vs. $100 \mathrm{yr}$ of synthetic weather data. In general, there was good agreement between observed and synthetic weather. Note that the direct validation for the other stations yielded similar results.

For the indirect validation, Fig. 3 (top row) shows the distributions of the start of the first flight of the codling moth in spring from observed and synthetic weather, as well as the in situ observed first flight activity from traps. The location was again Wädenswil where comprehensive phenological observations are available. There was good agreement between the synthetic weather for today's climate and both the in situ observations and the flight start simulated from the observed weather, both in terms of the median flight start (around midMay) and the shape and spread of the distributions. This was also confirmed by the non-significance of the applied nonparametric Wilcoxon-Mann-Whitney (test for shift in location) and Kolmogorov-Smirnov (test for the equality of continuous probability distributions) tests. Note that the in situ observed first flight activity is expected to lag behind the actual flight start as the traps are only controlled weekly (i.e. actual catch during previous week) and it takes some time until the moths are captured by the traps (H. Höhn, personal communication, 2011). As for the flight start, there was also general good agreement between observations-derived and synthetic weather-derived mean occurrences of the later codling moth life phases (Fig. 1 in the Supplement). Again, the validation for the other stations yielded similar results.

For fire blight, Fig. 3 (bottom row) displays histograms of the number of infection days per year from observed and from $100 \mathrm{yr}$ of synthetic weather for today's climate in Wädenswil. The majority of the years (approx. 60\%) showed no infection days, while in the remaining years, this number ranged from 1 to 7 . Both applied non-parametric tests, i.e. the Wilcoxon-Mann-Whitney and the KolmogorovSmirnov tests, indicated no significant difference between the distributions from observed and synthetic weather. Also, the Binomial test applied on the categories occurrence and non-occurrence of infection in a particular year indicated no significant deviation between infections from observed and synthetic weather. Sensitivity tests with applying relative humidity thresholds between $71 \%$ and $87 \%$ (see Sect. 2.3.2) demonstrated that the choice of the threshold was of minor importance for the resulting occurrence of infection days. In particular, the indirect validation always showed good agreement (i.e. non-significance in the mentioned tests, $5 \%$ 

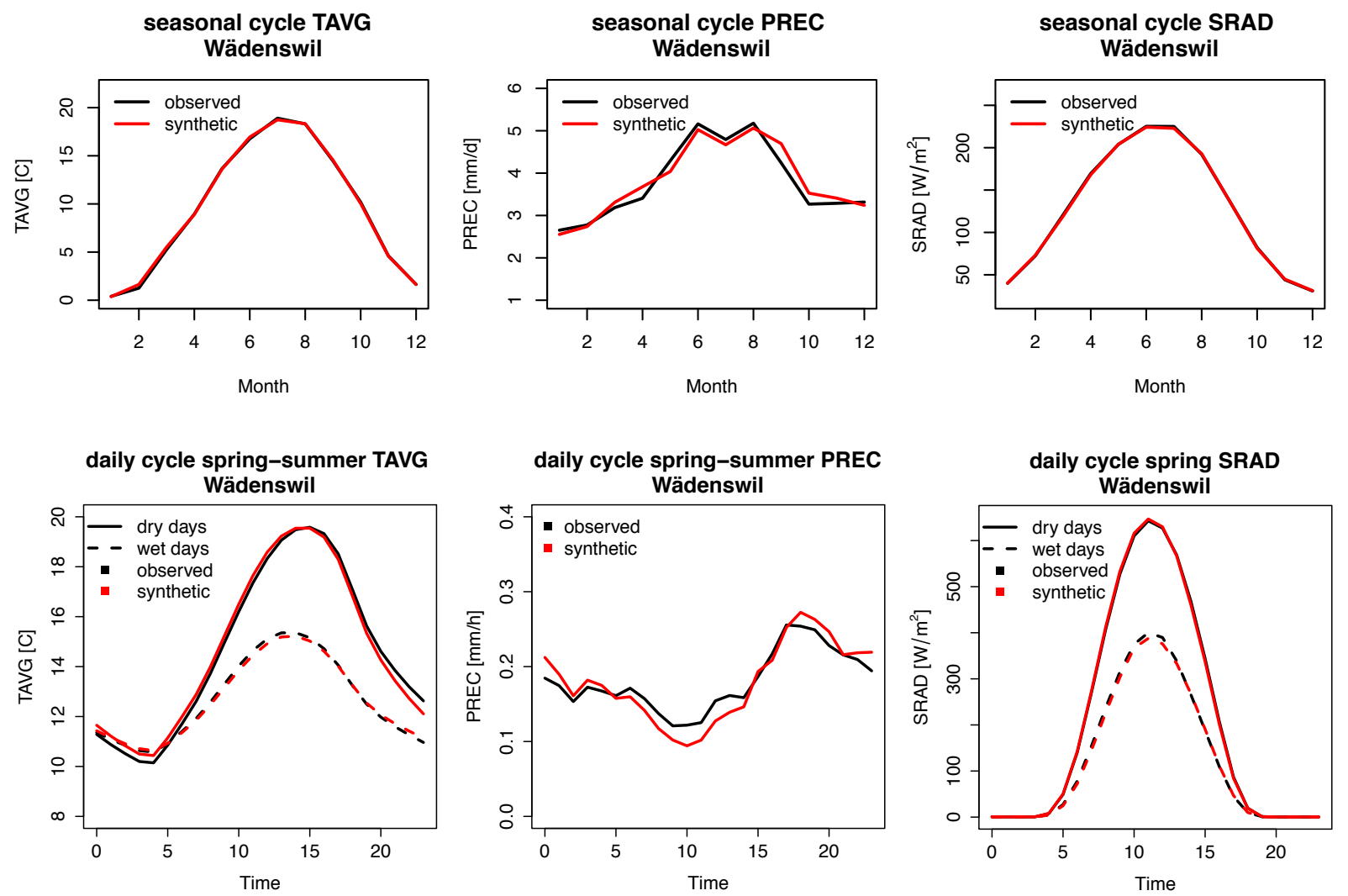

Fig. 2. Seasonal (top row) and daily (bottom row) cycles of mean temperature (TAVG), precipitation (PREC) and global solar radiation (SRAD) for the station Wädenswil. Synthetic data are displayed in red, observed data in black. Daily cycles are shown for spring and summer in case of temperature and precipitation, and for spring in case of solar radiation (as only the codling moth flight start in spring is influenced by solar radiation). For temperature and radiation, results are presented separately for dry and wet days. Database is 29 yr of in situ observations (1981-2009) and $100 \mathrm{yr}$ of synthetic weather.

significance levels) between the distributions of yearly infection days from observed and today's synthetic weather.

Overall, both the direct and indirect validation revealed a good quality of the generated synthetic weather data and the applied downscaling procedure appeared capable of reproducing the important weather characteristics for the applied pest and disease models.

\subsection{Climate change signals}

A short summary on the climate change signals in mean temperature and precipitation, as well as on the derived changes in precipitation parameters from the daily output of the ENSEMBLES RCMs is given here. The latter were used for the fire blight simulations and include changes in precipitation frequency and intensity, and in the transition probability from dry-to-wet used in the Markov model of the stochastic WG. Note that the adjustments of the original median climate change signals of precipitation frequency required to fulfill Eq. (1) (see Sect. 2.1) did not amount to more than $2 \%$.
The median climate change signals (2045-2074 vs. 19802009) from the multi-model projections showed significantly increasing mean temperatures in all seasons and domains, with the most pronounced signal in CHS (Table 1). Mean precipitation significantly decreased only in the summer season, consistent with the large-scale European precipitation response over Central Europe (see Fischer et al., 2011). Further analysis of the additional precipitation parameters revealed that this projected summer decrease in future mean precipitation was connected with a significant decrease in precipitation frequency in all domains, while precipitation intensity did not show a significant change in this season. Also, summer dry-to-wet transition probability was projected to significantly decrease in all domains, which was connected with an increase in the length of the dry spells in this season (not shown). For spring, no significant changes in mean precipitation and frequency were projected for the CHNE and CHW domains. The overall indifference of mean precipitation seemed to be composed of contrasting tendencies in intensity and frequency in these domains. 

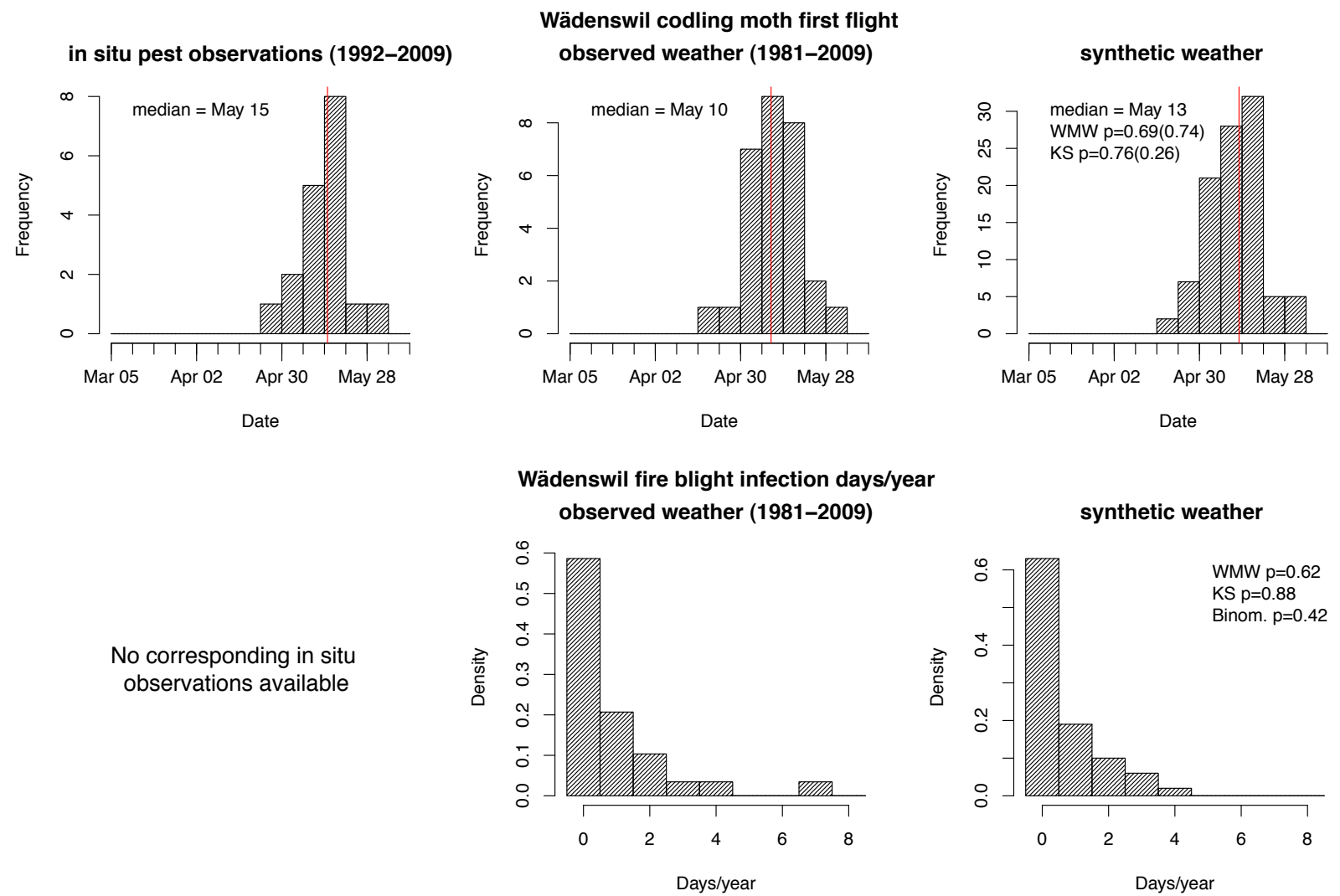

Fig. 3. Top row: in situ observations of first flight activity of codling moth in spring (left panel), as well as modeled flight start based on observed weather (middle panel) and based on present-day synthetic weather (right panel, station Wädenswil). The vertical red lines display the medians of the distributions. Bottom row: modeled number of fire blight infection days per year based on observed weather (middle panel) and based on present-day synthetic weather (right panel). In the right panels, the p-values for the Wilcoxon-Mann-Whitney (WMW) and the Kolmogorov-Smirnov (KS) tests are displayed for the difference between the distributions from synthetic weather and from observed weather (respectively, from in situ observations in brackets, if available). For fire blight, also the p-values of the Binomial test applied on the annual occurrence and non-occurrence of infections is shown.

\subsection{Pest scenarios}

\subsubsection{Codling moth}

The scenarios for the codling moth showed a shift of almost two weeks toward an earlier flight start under future climate conditions (considering the median climate change signal, Fig. 4). The applied statistical tests (Wilcoxon-MannWhitney and Kolmogorov-Smirnov) confirmed the difference of the tested distributions at high probabilities (see inlets in Fig. 4). An indication for such a shift could be documented in yearly in situ observations of first flight activity at the Magadino site from 1972-2010. On average, the first flights advanced three days per decade (unpublished data).

Figure 5 displays the occurrence of important codling moth life phases from synthetic weather representing $100 \mathrm{yr}$ in present and future climate, respectively (for the stations Wädenswil and Magadino), using the median climate change signal of the multi-model projections (see Sect. 2.1). A shift toward earlier occurrence was observed for all phases, ranging from two weeks for the flight start in spring (see also Fig. 4) to over three weeks for the later life phases. Connected with this, the sequence of the phases was accelerated under future climate conditions, as indicated by the increased slope of the red vs. the blue boxes.

The numbers on the right of the panels of Fig. 5 denote the percentage of years when the respective phase was reached in today's and future climate. This can be interpreted as the potential risk of reaching a respective phase based on the climatic conditions. While the potential for a 3rd generation was almost zero in today's climate in Wädenswil (only $1 \%$ potential risk for damage-causing larvae of the 3rd generation, see phase "Start larvae hatch gen3" in Fig. 5), the potential risk increased to $87 \%$ in the future for the median climate change signal. For the station Magadino, the potential for 3rd generation larvae already existed in today's climate ( $98 \%$ potential risk). Considering the uncertainty range of the projections (as represented by the three combinations of temperature and precipitation change signals mentioned in Sect. 2.1), the shifts in the occurrence of the life phases 

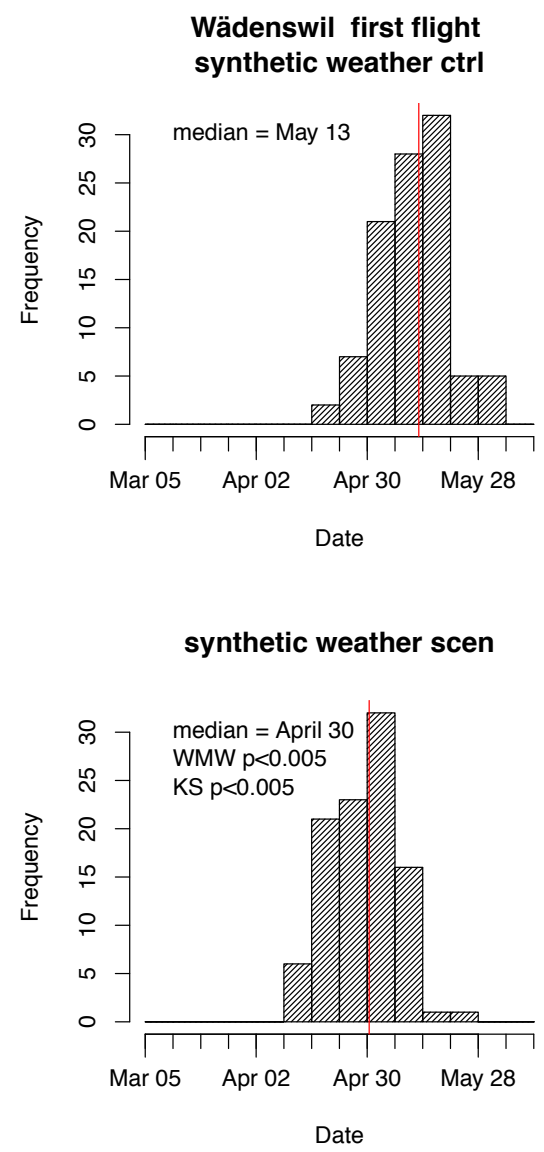
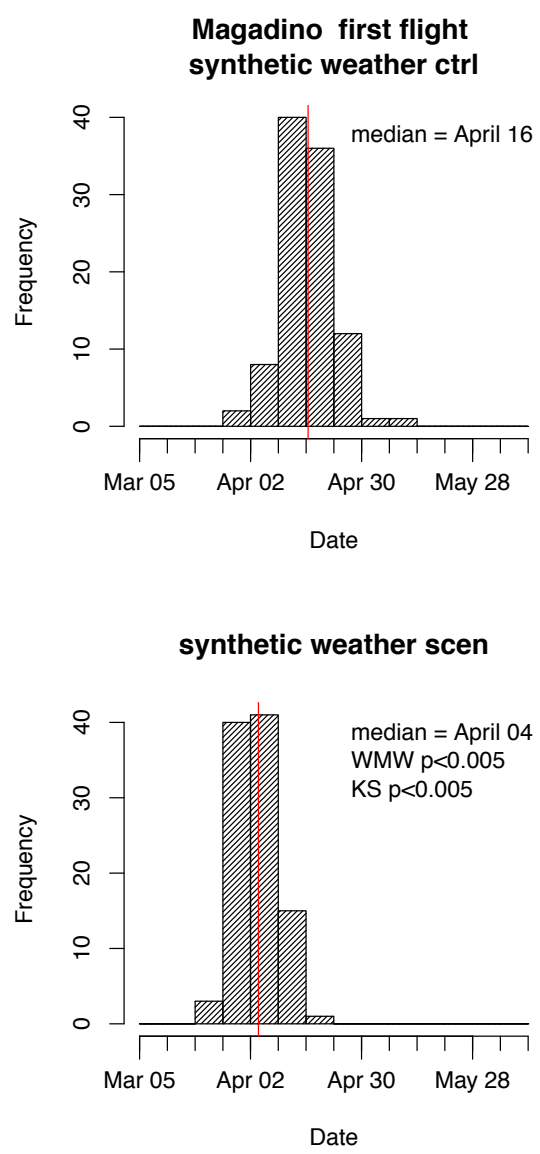

Fig. 4. As Fig. 3 (top row), but for the flight start in spring from synthetic weather for present ("ctrl", top panel) and future ("scen", bottom panel) climate at the stations Wädenswil (left panels) and Magadino (right panels). In the bottom panels, the p-values for the WilcoxonMann-Whitney (WMW) and the Kolmogorov-Smirnov (KS) tests are displayed for the difference between flight start from present-day and future synthetic weather.

are displayed in Fig. 2 in the Supplement, and the resulting increases in the potential risk for 3rd generation larvae are listed in Table 2 for all stations. This potential risk increased from $1 \%$ today to $26-100 \%$ for Wädenswil (Table 2). Most stations in northern Switzerland had a low potential risk for a 3rd generation in today's climate. In the future, this was projected to increase up to $100 \%$ (except for the higher altitude station St. Gallen).

In order to assure the consistency between the SOPRA system and the indicative temperature sums (see Sect. 2.3.1), their outputs for present and future climate were intercompared (see Fig. 3 in the Supplement). This comparison revealed a good agreement in the dates of occurrence of the different life phases (both in terms of mean occurrence and inter-annual variability), as well as in the displayed percentage of years of reaching the respective life phases (and thus the potential risk for these life phases).

To investigate the sensitivity of the codling moth with respect to temperature and precipitation changes over a wider range, impact response surfaces (e.g. Morse et al., 2009) of the potential risk for 3 rd generation larvae were constructed and compared with the uncertainty range of the modelprojected climate change (Fig. 6). The response surfaces are based on 300 30-yr simulations generated by adjusting the seasonal median change signals of mean temperature and precipitation. This enabled detection of non-linearity in the response of the pest model to climate change, and determination of robustness of the individual climate model responses with respect to the impact. As expected, there was an increase of the potential risk with increasing temperatures, but no response (except for some random variability from the applied stochastic WG) to changes in precipitation as the development of the codling moth is primarily dependent on temperature. The increase in the potential risk with temperature was not linear, but slower at the two ends of the value range. If the significance of the potential risk is judged relative to a threshold (i.e. some level of risk considered as unacceptable by the farmer), then the risk of this threshold being exceeded can be estimated as the proportion of the climate models' uncertainty range being situated in the exceedance zone. For Wädenswil, about one third of the climate models' uncertainty range in temperature reached $\geq 95 \%$ potential risk for 

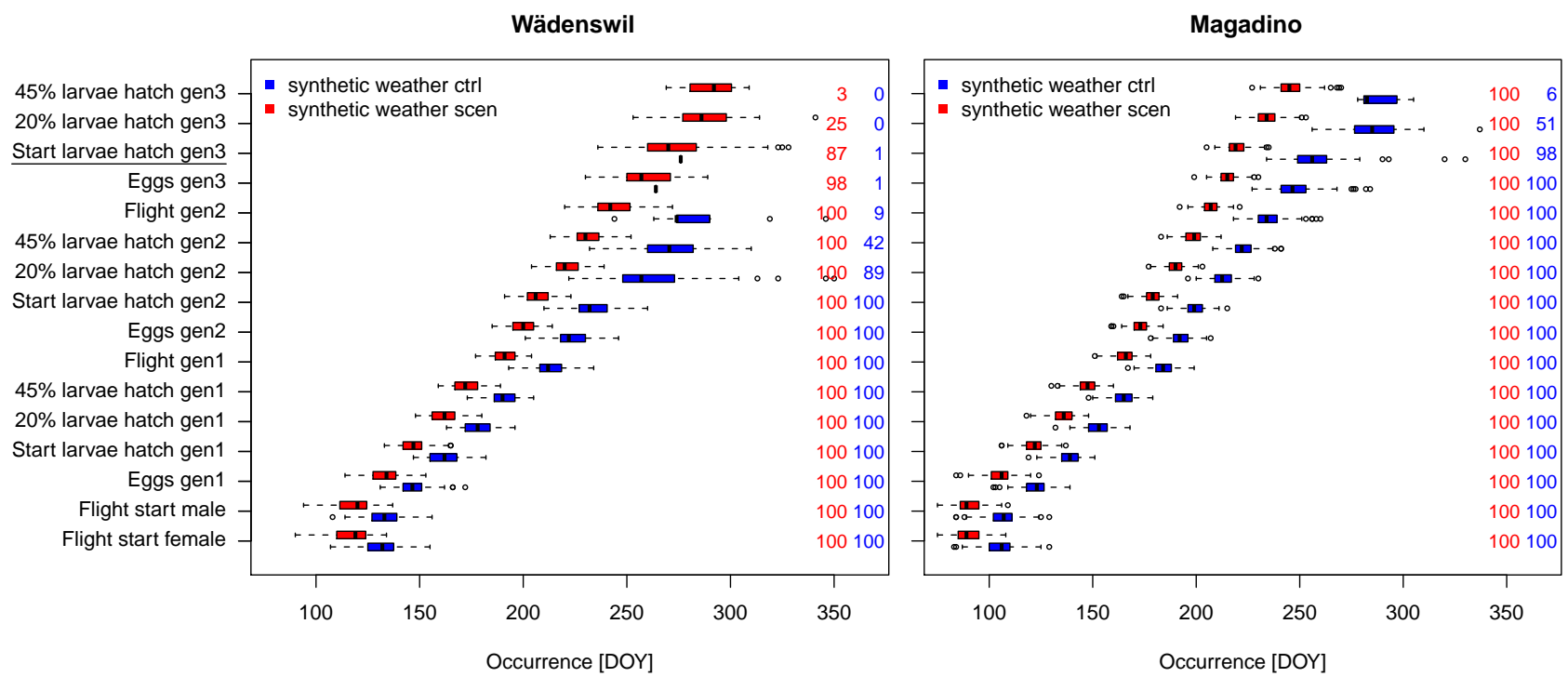

Fig. 5. Occurrences of important codling moth life phases for present ("ctrl", blue) and future ("scen", red, median signal of the multimodel projections) climate at the stations Wädenswil (left panel) and Magadino (right panel). The y-axes display the life phases for three generations (denoted "gen1-3") over one year (see Sect. 2.3.1), starting with the flight start in spring (corresponding to Fig. 4, but separately for male and female adults). The boxplots were derived from synthetic weather data representing $100 \mathrm{yr}$ in the present and future climate. The numbers on the right of the panels denote the percentage of years when the respective phase was reached based on the respective climate. The underlined phase "Start larvae hatch gen3" was used for the assessment of the potential risk of a 3rd codling moth generation.

Table 2. Potential risk for 3rd generation larvae (in \%) of codling moth at the various stations for today's climate and for the three considered combinations of temperature $(T)$ and precipitation $(P)$ change signals described in Sect. 2.1. Station name abbreviations are given in brackets (see Fig. 1 for their locations).

\begin{tabular}{lrrrr}
\hline Station & today & $\begin{array}{r}\text { low } T \\
\text { (high } P \text { ) }\end{array}$ & $\begin{array}{r}\text { med } T \\
(\text { med } P \text { ) }\end{array}$ & $\begin{array}{r}\text { high } T \\
\text { low } P \text { ) } \\
\text { signals }\end{array}$ \\
\hline Bern (BER) & 0 & 20 & 74 & 97 \\
Basel (BAS) & 6 & 78 & 99 & 100 \\
Buchs (BUS) & 0 & 43 & 92 & 100 \\
Chur (CHU) & 2 & 65 & 98 & 100 \\
Güttingen (GUT) & 0 & 13 & 66 & 99 \\
St. Gallen (STG) & 0 & 1 & 10 & 60 \\
Wädenswil (WAE) & 1 & 26 & 87 & 100 \\
Changins (CGI) & 3 & 88 & 100 & 100 \\
Sion (SIO) & 18 & 98 & 100 & 100 \\
Magadino (MAG) & 98 & 100 & 100 & 100 \\
\hline
\end{tabular}

3rd generation larvae. For the station Changins, this proportion was even larger and the majority of the models' uncertainty range was within the $\geq 95 \%$ potential risk area.

However, also factors other than temperature influence the development of the codling moth. In particular, the start of the hibernation (and thus the absence of later life phases) is induced by a day-length signal that the larvae perceive (photoperiodic diapause induction). In today's climate, this signal occurs roughly around end of July at $47^{\circ} \mathrm{N}$ (DOY 206, corresponding to a critical photoperiod of $16 \mathrm{~h}$; Riedl, 1983). However it is expected to shift to later dates (i.e. shorter day length) with the adaptation of the codling moth to warmer climate. Already with recent climate change, a decline in the critical photoperiod was observed for various species (e.g. for the pitcher plant mosquito; Bradshaw and Holzapfel, 2001). The scenarios presented so far ignored the photoperiodic diapause induction, thus we used the term "potential risk" to refer to the maximum risk based on the projected temperature increase. To what extent this risk will be reached in the future depends on the actual adaptation of the codling moth as expressed by the shift of the day-length signal. Sensitivity simulations with SOPRA including the effect of photoperiodic diapause induction showed that a shift of today's day-length signal (DOY 206) up to 40 days (until beginning of September, DOY 246) will lead to an increasing exploitation of the potential risk for 3rd generation larvae (referred to as actual risk, Fig. 7). It became evident that the actual risk of a 3rd generation in a future climate will critically depend on the pace of such an adaptation. However, the probable amount of such a shift is difficult to assess and subject to current research. Nevertheless, our results provided first conclusions irrespective of assumptions on this important factor. In southern Switzerland (station Magadino), today's exception of a 3rd generation (when including the effect of diapause induction) was projected to become the rule in the future, whereas three generations seemed unlikely without a 

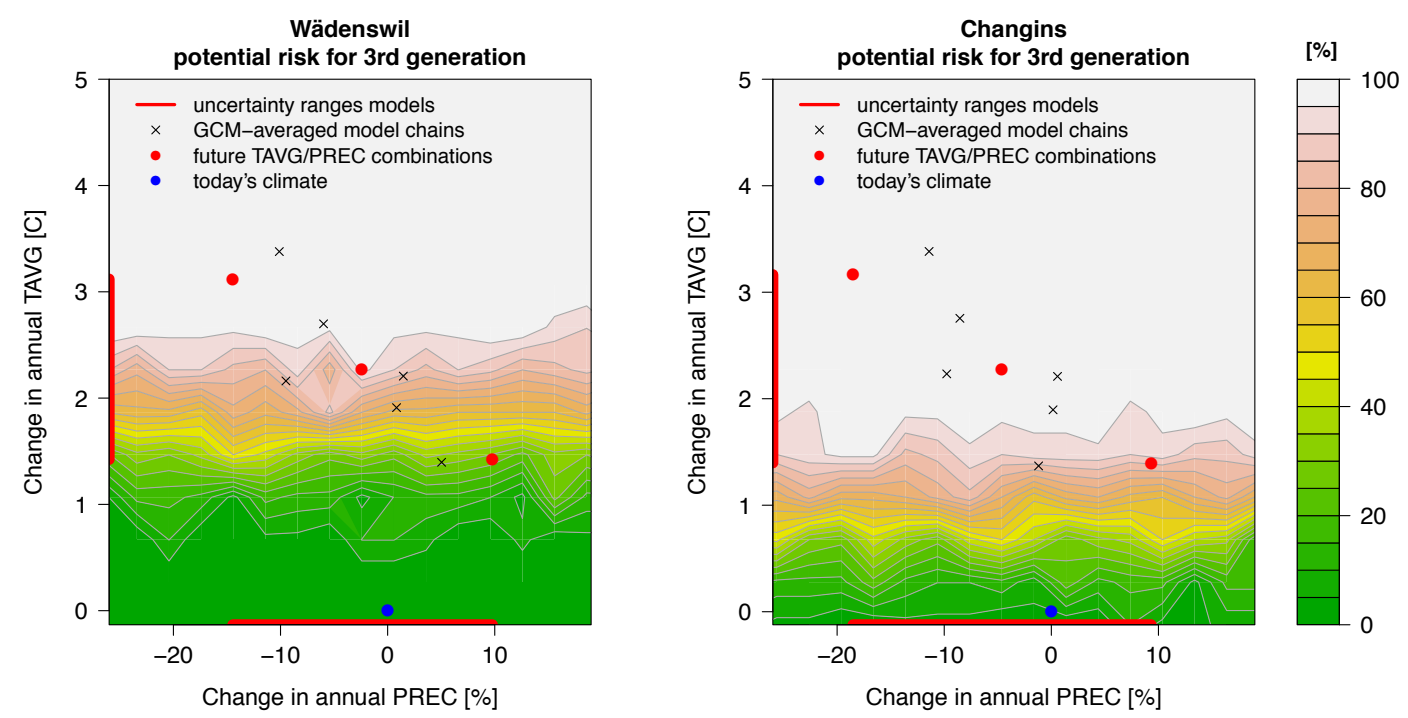

Fig. 6. Impact response surfaces of the potential risk for 3rd generation larvae at the stations Wädenswil (left panel) and Changins (right panel). The blue dot marks the potential risk in today's climate and the red dots refer to the three considered future combinations of temperature and precipitation changes (see Sect. 2.1). The crosses mark the raw model projections averaged according to the driving GCM. The red lines along the $\mathrm{x}$ - and $\mathrm{y}$-axes display the posterior uncertainty ranges of the model-projected changes in annual temperature and precipitation. The posterior distributions of these climate change signals were determined through application of the Bayesian multi-model combination algorithm independently to temperature and precipitation (Fischer et al., 2011). However, previous analyses of GCM/RCM outputs (e.g. Schär et al., 2004; Vidale et al., 2007) have shown that for the Alpine region, changes in temperature and precipitation tend to be negatively correlated, at least during the summer season, a tendency also found here with respect to the distribution of temperature and precipitation changes for the GCM-averaged model chains.

shift of the day-length signal in locations like St. Gallen or Wädenswil, and rare in Basel. A shift of 10 (20) days was needed to increase the actual 3rd generation larvae risk to approx. $20 \%$ in Basel (Wädenswil) in case of a median climate change, while the increase was only marginal at the elevated site St. Gallen even with a large shortening of the critical photoperiod.

\subsubsection{Fire blight}

In the case of fire blight disease, the median climate change signals for temperature and the precipitation parameters frequency, intensity and dry-to-wet transition probability led to no significant difference between present and future number of infection days for Wädenswil (Fig. 8). This was also the case for the other stations in northern Switzerland. The only station showing a slight but significant (5\% significance level) change in the distribution of infection days per year was Magadino in southern Switzerland (confirmed by the non-parametric Wilcoxon-Mann-Whitney test, as well as the Binomial test for annual infection occurrence).

The projected signal in spring precipitation frequency for northern Switzerland was weak to slightly negative (Table 1) and thus not expected to strongly contribute to enhanced infections. In addition, although the cumulative degree-hours (cDH, see Sect. 2.3.2) increased with increasing temperature, the blooming period at the same time shifted to earlier dates, which compensated the temperature effect on the cDH (Fig. 4 in the Supplement). This did not seem to be the case for Magadino. There, precipitation frequency showed a significant decrease in spring, and thus the projected enhancement of infection days must be induced by the temperature increase.

Note that the projected shift in the blooming period simply reflects the temperature increase. Other factors such as photoperiodicity or a prolongation of the chilling period due to higher winter temperatures (e.g. Morin et al., 2009) might reduce this shift in the blooming period, which would in term allow for a stronger effect of the temperature increase on the cDH. However, such processes were not included in the simple temperature-sum based blooming model used here. Furthermore, the blooming model was calibrated for "Golden Delicious" and the results thus might be different for other apple cultivars with divergent blooming periods. Another source of uncertainty in these results is the applied simple relative humidity-based threshold model for leaf wetness. However, as for the indirect validation, sensitivity tests with relative humidity thresholds ranging from $71 \%$ to $87 \%$ showed that the threshold had only minor influence on the resulting changes in infection days, i.e. the (non-)significance of changes thereof with climate change was a robust feature. This also justifies our conservative assumption of not including a climate change signal for relative humidity (see Sect. 2.1). 

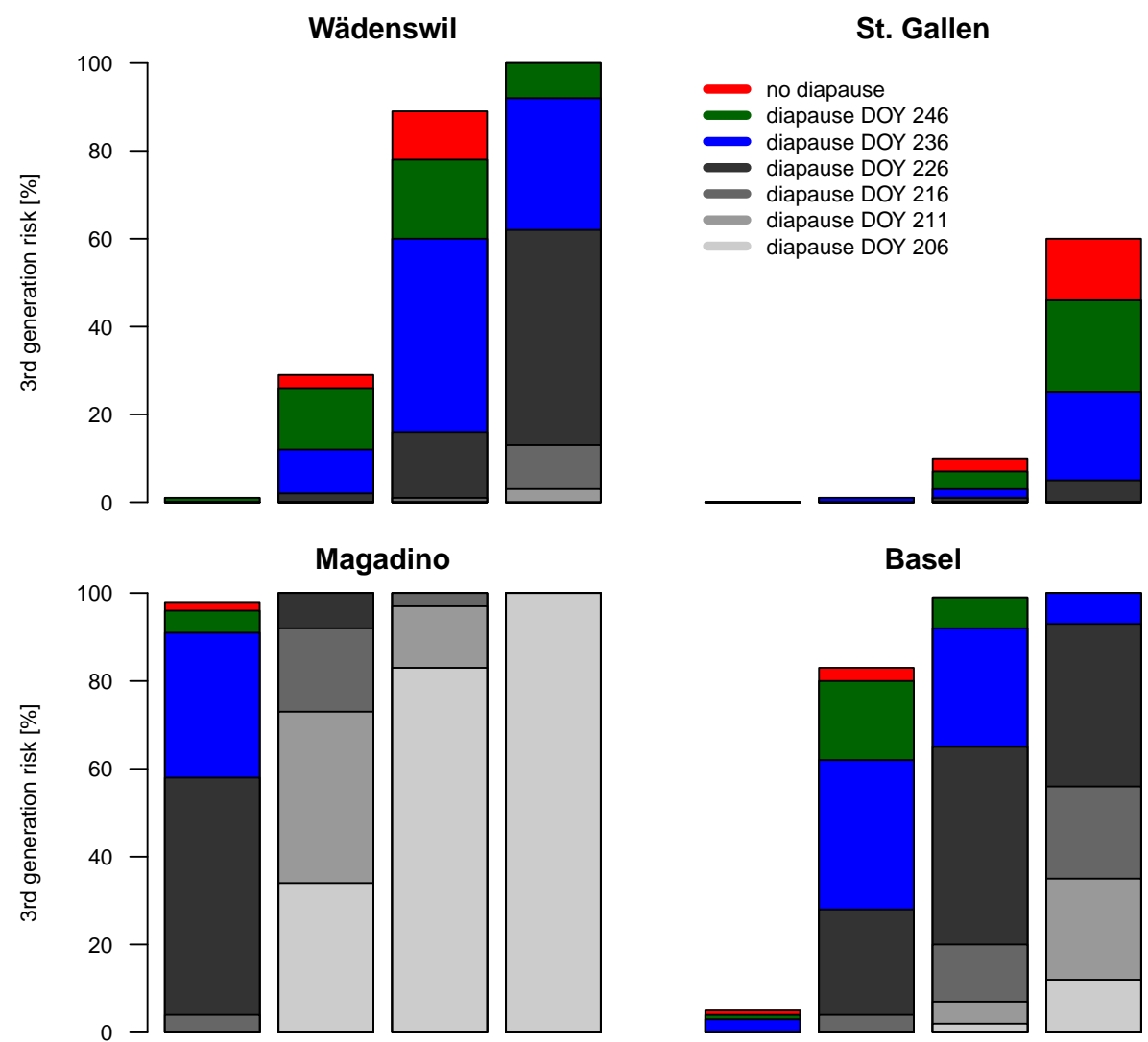

Magadino
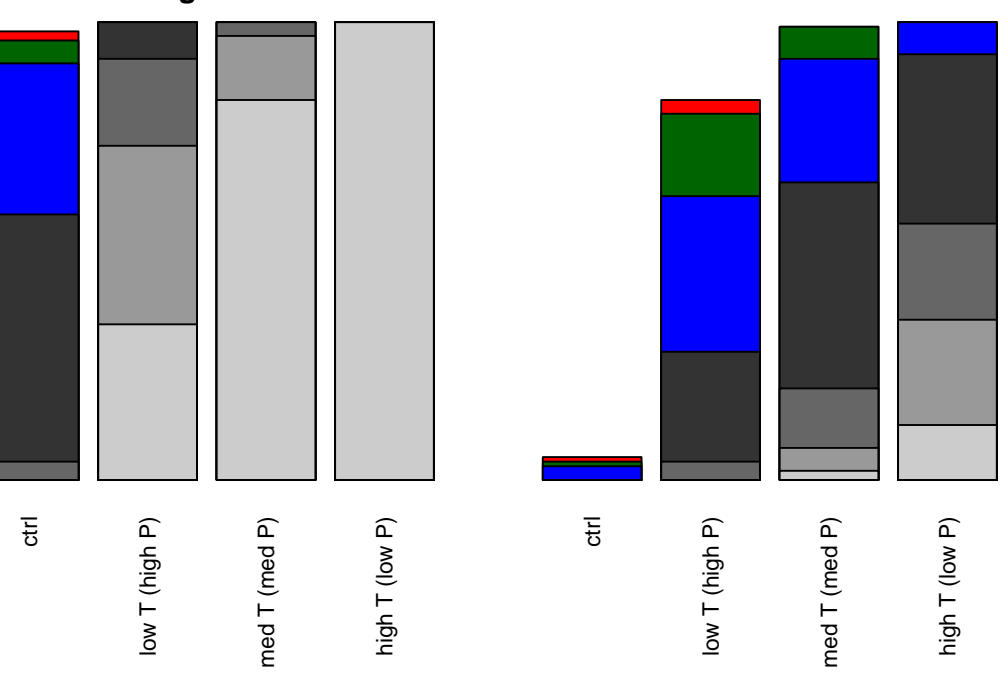

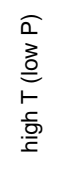

\begin{tabular}{|c|c|}
\hline$\widehat{\underline{x}}$ & $\widetilde{\alpha}$ \\
\hline 들 & ర్ల \\
\hline$\check{\vdash}$ & $\stackrel{F}{\vdash}$ \\
\hline 흐 & ర్ల \\
\hline
\end{tabular}

Fig. 7. Sensitivity of the 3rd generation larvae risk on the shift of the day-length signal for diapause induction in today's ("ctrl") and future climate (i.e. the three considered combinations of temperature and precipitation change signals, see Sect. 2.1). The actual risks for today's day-length signal (DOY 206) and for shifts of this signal up to 40 days (DOY 246) are shown. As a reference, also the potential risk for no diapause induction (representing the potential risk as derived from the indicative temperature sums, Table 2) is displayed.

\section{Summary and conclusions}

We analyzed the effect of climate change on the agricultural pest codling moth and disease fire blight in Switzerland. The analysis was based on multi-model regional climate projections from the ENSEMBLES project, a subsequent downscaling procedure to derive hourly weather series and the modeling of the pest and disease evolution with two models operationally used for decision support. The downscaling procedure consisted of the stochastic WG M\&Rfi (Dubrovsky et al., 2004) to obtain daily weather series, and a subsequent $k$-nearest neighbor re-sampling for the derivation of hourly weather series.

The results for codling moth indicated a shift in the occurrence and duration of life phases relevant for pest control under future climate conditions. In southern Switzerland (station Magadino), today's exception of a 3rd generation was projected to become the rule in the 2045-2074 time period. While the potential risk for a 3rd generation was also significantly increasing in northern Switzerland (for most stations from roughly $1 \%$ on average today to over $60 \%$ in 2045-2074 for the median climate change signal of the multi-model projections), the actual risk will critically depend on the pace of the adaptation of the codling moth with respect to the critical photoperiod. A shift of 10 and 20 days in the corresponding day-length signal was needed to increase the actual risk for hatching 3rd generation larvae to approx. $20 \%$ in Basel and Wädenswil, respectively. To control this additional generation, higher and prolonged control efforts will be necessary, implying repeated treatments. This increases the risk for emerging insecticide resistances (e.g. Asser-Kaiser et al., 2007; Reyes et al., 2007; Kutinkova et al., 2010) and would require large efforts in order to assure sustainability of codling moth control in the future (Samietz et al., 2012; Stoeckli et al., 2012). 

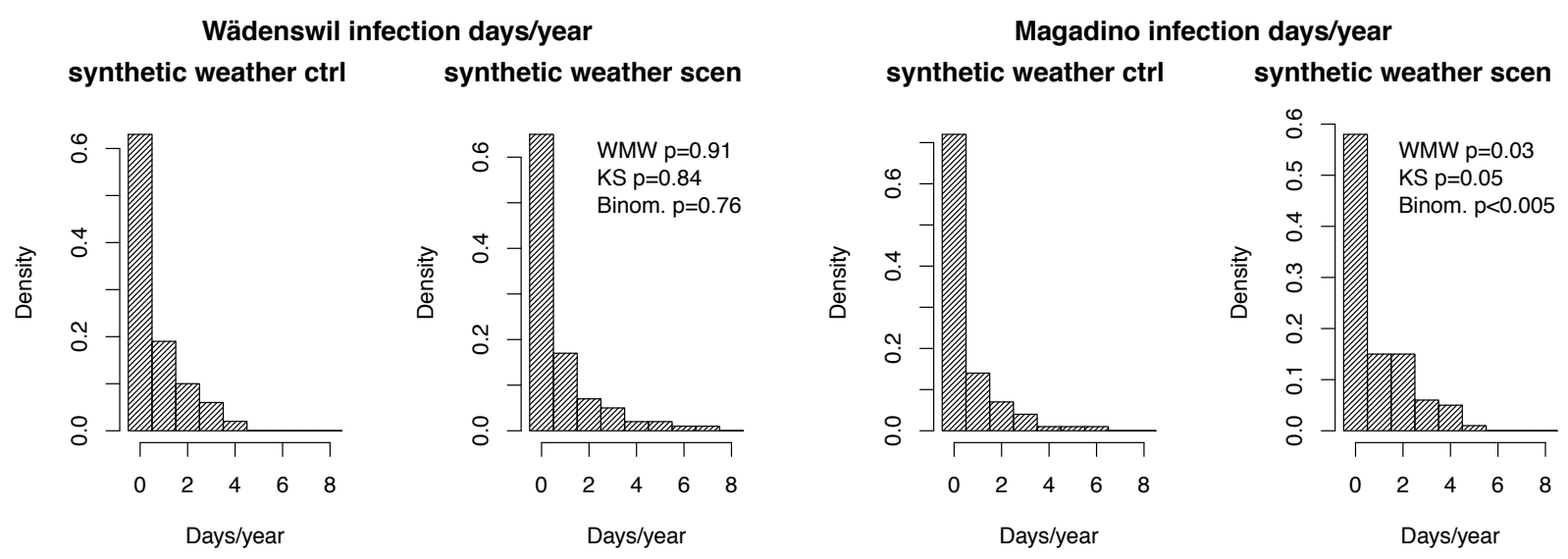

Fig. 8. As Fig. 3 (bottom row), but for the number of fire blight infection days per year from synthetic weather for present ("ctrl”) and future ("scen") at the stations Wädenswil (left panels) and Magadino (right panels).

For the bacterial disease fire blight, no significant change in the number of yearly infection days could be detected in northern Switzerland, based on the median climate change signals of temperature, precipitation frequency and intensity, and the transition probability from dry-to-wet days. The reasons for this insensitivity of fire blight to climate change were a shift of the blooming period to earlier dates, which compensated for the temperature increase, and the only weak climate change signal in spring precipitation. Only the station Magadino in southern Switzerland showed a significant change in the distribution of yearly infection days. The results for fire blight are associated with a relatively high degree of uncertainty due to the applied simple temperature-based blooming model and the simple leaf wetness calculation.

Our current analyses are primarily based on changes in climate conditions between present and future climate (except for the additional inclusion of the day-length signal shift), and depend on the validity of the described impact models. Factors as the genetic adaptation of the pests to future climate conditions or the influence of fixed or non-fixed photoperiodic signals might relativize or strengthen the impact of climate change on the specific pest or disease, and are subject to current and future research in the biological field.

\section{Supplementary material related to this article is available online at: http://www.earth-syst-dynam.net/3/33/2012/ esd-3-33-2012-supplement.pdf.}

Acknowledgements. The development of the weather generator is supported by the GAAV Grant Agency (project IAA300420806). Funding for the downscaling and pest simulation experiments was provided by the Swiss State Secretariat for Education and Research SER (grant number C09.0052) in the framework of COST 734 action (Impacts of Climate Change and Variability on European Agriculture - CLIVAGRI), the National Centre of Competence in Research on Climate (NCCR Climate) of the Swiss National Science Foundation and the EU Interreg IV project "Gemeinsam gegen Feuerbrand". We acknowledge the RCM data sets from the EU-FP6 project ENSEMBLES (http://ensembles-eu.metoffice.com). We also thank E. Moltmann, LTZ-Augustenberg, Germany, for providing an adjusted version of Maryblyt.

Edited by: N. de Noblet

\section{References}

Altermatt, F.: Climatic warming increases voltinism in European butterflies and moths, P. Roy. Soc. B, 277, 1281-1287, doi:10.1098/rspb.2009.1910, 2010.

Asser-Kaiser, S., Fritsch, E., Undorf-Spahn, K., Kienzle, J., Eberle, K. E., Gund, N. A., Reineke, A., Zebitz, C. P. W., Heckel, D. G., Huber, J., and Jehle, J. A.: Rapid Emergence of Baculovirus Resistance in Codling Moth Due to Dominant, Sex-Linked Inheritance, Science, 317, 1916-1918, doi:10.1126/science.1146542, 2007.

Bonn, W. and van der Zwet, T.: Distribution and economic importance of fire blight, in: Fire Blight: The Disease and its Causative Agent, Erwinia amylovora, edited by: Vanneste, J., CABI Publishing, Wollingford, UK, 37-53, 2000.

Bradshaw, W. E. and Holzapfel, C. M.: Genetic shift in photoperiodic response correlated with global warming, P. Natl. Acad. Sci. USA, 98, 14509-14511, doi:10.1073/pnas.241391498, 2001.

Braun-Kiewnick, A., Altenbach, D., Oberhänsli, T., Bitterlin, W., and Duffy, B.: A rapid lateral-flow immunoassay for phytosanitary detection of Erwinia amylovora and on-site fire blight diagnosis, J. Microbiol. Meth., 87, 1-9, doi:10.1016/j.mimet.2011.06.015, 2011.

Buser, C., Künsch, H., Lüthi, D., Wild, M., and Schär, C.: Bayesian multi-model projection of climate: bias assumptions and interannual variability, Clim. Dynam., 33, 849-868, doi:10.1007/s00382-009-0588-6, 2009.

Calanca, P., Bogatai, L., Halenka, T., Cloppet, E., and Mika, J.: Use of climate change scenarios in agrometeorological studies: past experience and future needs, in: Survey of agrometoeorlogical 
practices and applications in Europe regarding climate change impacts, edited by: Nejedlik, P. and Orlandini, S., COST ESSEM publication, 237-266, 2009.

Christensen, J. H. and Christensen, O. B.: Climate modelling: Severe summertime flooding in Europe, Nature, 421, 805-806, 2003.

Coakley, S. M., Scherm, H., and Chakraborty, S.: Climate change and plant disease management, Annu. Rev. Phytopathol., 37, 399-426, doi:10.1146/annurev.phyto.37.1.399, 1999.

Dorn, S., Schumacher, P., Abivardi, C., and Meyhöfer, R.: Global and regional pest insects and their antagonists in orchards: spatial dynamics, Agr. Ecosyst. Environ., 73, 111-118, 1999.

Dubrovsky, M., Zalud, Z., and M. S.: Sensitivity of CERESMaize yields to statistical structure of daily weather series, Clim. Change, 46, 447-472, doi:10.1023/A:1005681809065, 2000.

Dubrovsky, M., Buchtele, J., and Zalud, Z.: High-frequency and low-frequency variability in stochastic daily weather generator and its effect on agricultural and hydrologic modelling, Climatic Change, 63, 145-179, 2004.

Dubrovsky, M., Hirschi, M., and Spirig, C.: HOWGH: an hourly weather generator for pests modeling in present and future climates, in: Geophysical Research Abstracts, vol. 13, 2011.

Duffy, B., Schoch, B., Vogelsanger, J., Holliger, E., and Moltmann, E.: Fire blight forecasting model optimization in a user-friendly online interface, Acta Hortic., 803, 77-82, 2008.

Eastburn, D. M., McElrone, A. J., and Bilgin, D. D.: Influence of atmospheric and climatic change on plant-pathogen interactions, Plant. Pathol., 60, 54-69, doi:10.1111/j.13653059.2010.02402.x, 2011.

Fischer, A. M., Weigel, A. P., Buser, C., Knutti, R., Künsch, H. R., Liniger, M. A., Schär, C., and Appenzeller, C.: Climate Change Projections for Switzerland based on a Bayesian multi-model approach, Int. J. Climatol., doi:10.1002/joc.3396, in press, 2011.

Frei, C., Schöll, R., Fukutome, S., Schmidli, J., and Vidale, P. L.: Future change of precipitation extremes in Europe: Intercomparison of scenarios from regional climate models, J. Geophys. Res., 111, D06105, doi:10.1029/2005JD005965, 2006.

Hay, L. E., Wilby, R. L., and Leavesley, G. H.: A comparison of delta change and downscaled GCM scenarios for three mountainous basins in the United States, J. Am. Water Resour. As., 36, 387-397, doi:10.1111/j.1752-1688.2000.tb04276.x, 2000.

Hlavinka, P., Trnka, M., Semeradova, D., Dubrovsky, M., Zalud, Z., and Mozny, M.: Effect of drought on yield variability of key crops in Czech Republic, Agr. Forest Meteorol., 149, 431-442, 2009.

Howell, J. F. and Neven, L. G.: Physiological Development Time and Zero Development Temperature of the Codling Moth (Lepidoptera: Tortricidae), Environ. Entomol., 29, 766-772, doi:10.1603/0046-225X-29.4.766, 2000.

Janjua, N. A., Nasir, M. M., and Chaudhry, G. U.: The codling moth, Cydia pomonella (L.), Baluchistan, Biol. Soc. Pakistan Monog., 2, 1-122, 1958.

Jock, S., Donat, V., López, M. M., Bazzi, C., and Geider, K.: Following the spread of fire blight in Western, Central and Southern Europe by molecular differentiation of Erwinia amylovora strains with PFGE analysis, Environ. Microbiol., 4, 106-114, 2002 .
Kutinkova, H., Samietz, J., and Dzhuvinov, V.: Isomate C plus dispensers as alternative means for control of codling moth, Cydia pomonella (L.), in apple orchards of Bulgaria, IOBC/wprs Bulletin, 54, 657-662, 2010.

Meehl, G. A. and Tebaldi, C.: More Intense, More Frequent, and Longer Lasting Heat Waves in the 21st Century, Science, 305, 994-997, 2004.

Mezghani, A. and Hingray, B.: A combined downscalingdisaggregation weather generator for stochastic generation of multisite hourly weather variables over complex terrain: Development and multi-scale validation for the Upper Rhone River basin, J. Hydrol., 377, 245-260, 2009.

Morin, X., Lechowicz, M. J., Augspurger, C., O’Keefe, J., Viner, D., and Chuine, I.: Leaf phenology in 22 North American tree species during the 21 st century, Global Change Biol., 15, 961975, doi:10.1111/j.1365-2486.2008.01735.x, 2009.

Morse, A., Prentice, C., and Carter, T.: Assessments of climate change impacts, in: ENSEMBLES: Climate Change and its Impacts: Summary of research and results from the ENSEMBLES project, edited by: van der Linden, P. and Mitchell, J., chap. 9, Met Office Hadley Centre, FitzRoy Road, Exeter, EX1 3PB, UK, 107-129, 2009.

Nakicenovic, N., Alcamo, J., Davis, G., de Vries, B., Fenhann, J., Gaffin, S., Gregory, K., Grübler, A., Jung, T. Y., Kram, T., Rovere, E. L. L., Michaelis, L., Mori, S., Morita, T., Pepper, W., Pitcher, H., Price, L., Riahi, K., Roehrl, A., Rogner, H.-H., Sankovski, A., Schlesinger, M., Shukla, P., Smith, S., Swart, R., van Rooijen, S., Victor, N., and Dadi, Z.: Special Report on Emissions Scenarios: A Special Report of Working Group III of the Intergovernmental Panel on Climate Change, Cambridge University Press, Cambridge, UK, 2000.

Parmesan, C., Ryrholm, N., Stefanescu, C., Hill, J. K., Thomas, C. D., Descimon, H., Huntley, B., Kaila, L., Kullberg, J., Tammaru, T., Tennent, W. J., Thomas, J. A., and Warren, M.: Poleward shifts in geographical ranges of butterfly species associated with regional warming, Nature, 399, 579-583, doi:10.1038/21181, 1999.

Racsko, P., Szeidl, L., and Semenov, M.: A serial approach to local stochastic weather models, Ecol. Model., 57, 27-41, 1991.

Reyes, M., Franck, P., Charmillot, P.-J., Ioriatti, C., Olivares, J., Pasqualini, E., and Sauphanor, B.: Diversity of insecticide resistance mechanisms and spectrum in European populations of the codling moth, Cydia pomonella, Pest Manag. Sci., 63, 890-902, doi:10.1002/ps.1421, 2007.

Richardson, C. W.: Stochastic simulation of daily precipitation, temperature, and solar radiation, Water Resour. Res., 17, 182190, 1981.

Riedl, H.: Analysis of codling moth phenology in relation to latitude, climate and food availability, in: Diapause and Life Cycle Strategies in Insects, edited by: Brown, V. and Hodek, I., Dr. W. Junk Publishers, Netherlands, 233-252, 1983.

Samietz, J., Graf, B., Höhn, H., Schaub, L., and Höpli, H.: Phenology modelling of major insect pests in fruit orchards from biological basics to decision support: the forecasting tool SOPRA, Bulletin OEPP/EPPO, 37, 255-260, 2007.

Samietz, J., Graf, B., Höhn, H., Höpli, H., and Schaub, L.: SOPRA: phenology modelling of major orchard pests - from biological basics to decision support, Acta Hortic., 803, 35-42, 2008a. 
Samietz, J., Graf, B., Höhn, H., Schaub, L., and Höpli, H. U.: Schädlingsprognose für den Obstbau, Agrarforschung, 15, 208213, 2008b.

Samietz, J., Stoeckli, S., Hirschi, M., Spirig, C., Höhn, H., Calanca, P., and Rotach, M. W.: Modelling the impact of climate change on sustainable management of the codling moth (Cydia pomonella) as key pest in apple, Acta Hortic., in press, 2012.

Schär, C., Vidale, P. L., Lüthi, D., Frei, C., Häberli, C., Liniger, M. A., and Appenzeller, C.: The role of increasing temperature variability in European summer heatwaves, Nature, 427, 332336, doi:10.1038/nature02300, 2004.

Semenov, M., Donatelli, M., Stratonovitch, P., Chatzidaki, E., and Baruth, B.: ELPIS: a dataset of local-scale daily climate scenarios for Europe, Clim. Res., 44, 3-15, 2010.

Sherwood, S. C., Ingram, W., Tsushima, Y., Satoh, M., Roberts, M., Vidale, P. L., and O'Gorman, P. A.: Relative humidity changes in a warmer climate, J. Geophys. Res., 115, D09104, doi:10.1029/2009JD012585, 2010.

Solow, A.: Detecting Changes through Time in the Variance of a Long-Term Hemispheric Temperature Record: An Application of Robust Locally Weighted Regression, J. Climate, 1, 290-296, doi:10.1175/1520-0442(1988)001<0290:DCTTIT>2.0.CO;2, 1988.

Steiner, P.: Predicting Apple Blossom Infections by Erwinia amylovora Using the Maryblyt Model, Acta Hortic., 273, 139$148,1990$.

Steiner, P. and Lightner, G.: Maryblyt 4.3. A predictive program for forecasting fire blight diseases in apples and pears, Gemplers Inc., Mt. Hebron, Wisconsi, 53572, USA, 1996.

Stoeckli, S. and Samietz, J.: Simplified modelling of Apple flowering phenology for application in climate change scenarios, Acta Hortic., in press, 2012.

Stoeckli, S., Hirschi, M., Spirig, C., Calanca, P., Rotach, M. W., and Samietz, J.: Impact of climate change on voltinism and diapause induction of a global pest insect - Cydia pomonella (L.), PLoS ONE, cond. accepted, 2012.
Tebaldi, C. and Knutti, R.: The use of the multi-model ensemble in probabilistic climate projections, Philos. T. Roy. Soc. A, 365, 2053-2075, doi:10.1098/rsta.2007.2076, 2007.

Trnka, M., Muska, F., Semeradova, D., Dubrovsky, M., Kocmankova, E., and Zalud, Z.: European Corn Borer life stage model: Regional estimates of pest development and spatial distribution under present and future climate, Ecol. Model., 207, 61-84, 2007.

van der Linden, P. and Mitchell, J. F. B.: ENSEMBLES: Climate Change and its Impacts: Summary of research and results from the ENSEMBLES project, Tech. rep., Met Office Hadley Centre, Exeter, UK, 2009.

Van Jaarsveld, J.: The Operational Priority Substances model. Description and validation of OPS-Pro 4.1, Tech. Rep. 500045001, RIVM, Bilthoven, The Netherlands, 2004.

Vidale, P. L., Lüthi, D., Wegmann, R., and Schär, C.: European summer climate variability in a heterogeneous multi-model ensemble, Climatic Change, 81, 209-232, doi:10.1007/s10584006-9218-z, 2007.

Wichink Kruit, R., Jacobs, A., and Holtslag, A.: Measurements and estimates of leaf wetness over agricultural grassland for dry deposition modeling of trace gases, Atmos. Environ., 42, 53045316, doi:10.1016/j.atmosenv.2008.02.061, 2008.

Wild, M.: How well do IPCC-AR4/CMIP3 climate models simulate global dimming/brightening and twentieth-century daytime and nighttime warming?, J. Geophys. Res., 114, D00D11, doi:10.1029/2008JD011372, 2009.

Wilks, D. S.: Realizations of Daily Weather in Forecast Seasonal Climate, J. Hydrometeorol., 3, 195-207, doi:10.1175/15257541(2002)003<0195:RODWIF>2.0.CO;2, 2002.

Wilks, D. S. and Wilby, R. L.: The weather generation game: a review of stochastic weather models, Prog. Phys. Geogr., 23, 329$357,1999$. 